\title{
IN DEFENSE OF HNPS AS A'-MOVEMENT
}

\author{
TOSHIAKI NISHIHARA \\ Nagasaki University
}

\begin{abstract}
This paper aims to discuss some treatments of the non-canonical ordering observed in the phenomenon known as Heavy NP Shift, and to show that HNPS is best analyzed as $\mathrm{A}^{\prime}$ (rightward)-movement. Through discussion it will be shown that $\mathrm{A}^{\prime}$-movement analysis can provide natural explanations for some properties of HNPS. It will also be shown that an NP-Incorporation analysis proposed by Stowell (1981) may account for the impossibility of HNPS from the indirect object in the double object construction.*
\end{abstract}

\section{Introduction}

The phenomenon known as Heavy NP Shift (hereafter, HNPS), which is illustrated in (1), has been widely discussed thus far, and several characteristics of that phenomenon have been revealed in the literature of generative grammar.

(1) a. Mary gave everything that he demanded to John.

b. Mary gave to John everything that he demanded.

Opinions are, however, divergent about the grammatical mechanisms which account for the non-canonical ordering of the shifted NPs. Recent studies have argued for mechanisms different than the widely accepted $\mathrm{A}^{\prime}$ (rightward)-movement analysis of HNPS. In his article (1988a, 1988b) Larson suggests a leftward movement analysis of a predicate phrase, which produces the phenomenon, HNPS, while Nishikawa (1990) and Nakamura (1991), among others, have argued for an A-movement analysis of HNPS. In Section 1 we will review

* I would like to thank Thomas Wasow, Peter Culicover, and two anonymous $E L$ reviewers for their helpful comments and suggestions on an earlier draft. My thanks also go to Assunta Martin and Giles Parker for suggesting stylistic improvements. None of these people should be blamed for shortcomings in the present work. 
Larson's leftward movement analysis and discuss some of the problems with his analysis. In Section 2 we will see an A-movement analysis of HNPS, focusing on Nishikawa (1990), and we will present empirical evidence against the analysis. In Section 3 we will argue that $\mathrm{A}^{\prime}$ (rightward)-movement is favored since it can capture most of the properties of HNPS we discuss here. We also argue that an NPIncorporation analysis by Stowell (1981) provides an account for the fact that HNPS is not applicable to the first object in the double object construction.

\section{Leftward Movement Analysis of HNPS}

Larson (1988a, 1988b) suggests an analysis in which an NP does not move rightward, but other material moves leftward to yield (1b). His basic idea is based on two assumptions. The direct object NP originates in a pre-verbal position, specifically the Spec of the lower VP, in the so-called Larsonian VP shell. Second, the verb, along with other elements, moves leftward over the direct object NP. The latter process is permitted by a process of $\mathrm{V}^{\prime}$-reanalysis, which will be shown below. The leftward movement of the verb and other elements, as a unit, yields the HNPS example. If the $\mathrm{V}^{\prime}$-reanalysis does not apply and the verb moves alone into the empty higher $\mathrm{V}$ position, then this process yields (1a). (2) represents the process of $\mathrm{V}^{\prime}$-reanalysis, yielding (1b).
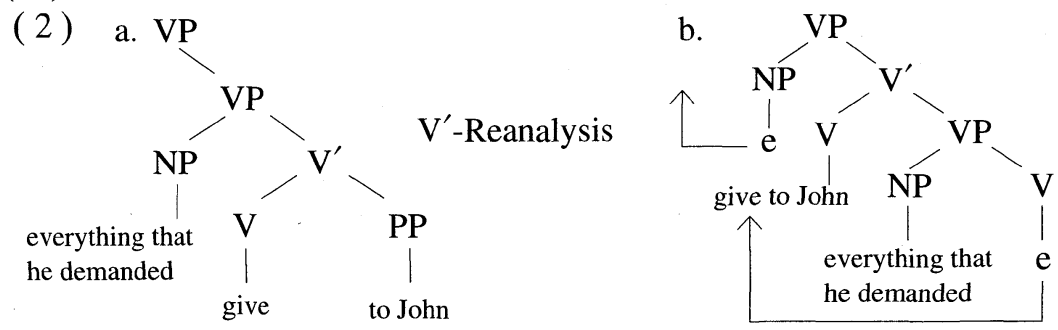

Larson's treatment of HNPS, though intriguing, has several problems. First, the mechanism of $V^{\prime}$-reanalysis collapses in the case of HNPS in the ECM (Exceptional Case Marking) construction. As has been noted in the literature, the embedded ECM subjects may undergo HNPS. This raises a question about Larson's analysis. Note that the syntactic category of ECM complements is crucial. Larson (1991) argues that the verb, allow, takes an ECM complement, which forms 
IP. The relevant structure of the ECM complement is:

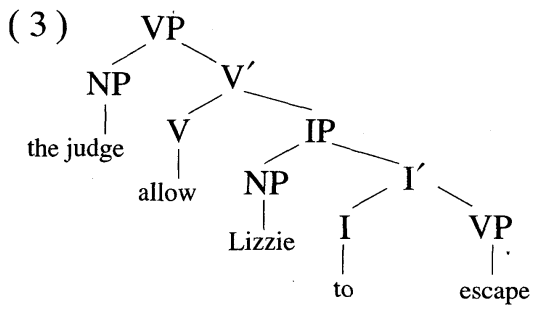

(Larson (1991: 136))

In (3) the verb and other material cannot move as a unit over the embedded subject NP since the $V^{\prime}$-reanalysis does not apply. Therefore as long as Larson assumes the structure (3), the HNPS case of the ECM embedded subject is not accounted for under his $V^{\prime}$-reanalysis.

The scope of the adverbial elements in the HNPS example of ECM poses another problem for Larson's analysis. Consider (4):

(4) a. The FBI believed the man they were after to be in hiding for a time.

b. The FBI believed to be in hiding for a time the man they were after.

The adverbial phrase in (4a) can modify either the matrix sentence or the embedded clause, and thus (4a) is ambiguous, with for a time modifying either believed or be in hiding. Once HNPS applies to the embedded subject in the ECM construction as in (4b), the interpretation of the adverbial is unambiguous. ${ }^{1}$ The adverbial modifies only the lower clause, including the moved NP. This non-ambiguity in modification cannot be coped with by Larson's analysis. As shown above, his analysis cannot provide any adequate derivation for HNPS in the ECM construction. Hence, it cannot offer any way to account for the non-ambiguity in the modification of for a time in (4b). In order to handle the modification non-ambiguity of the adverbial in (4b), Larson would propose a non-standard analysis of ECM, one in which the ECM verb and the infinitive form a $V^{\prime}$ constituent that

1 Johnson (1988) and Wasow (personal communication) claim that the adverbial in the HNPS example of ECM is unambiguous. We note that not all cases of the adverbials in the HNPS examples are unambiguous. The following example pointed out by Culicover (personal communication) suggests that the adverbial can modify the matrix clause since $\mathrm{PRO}$ in the adverbial must be controlled by a subject.

(i) Mary believed to be intelligent without actually deluding herself that man that she had just met. 
excludes the infinitive subject. ${ }^{2}$ Under this analysis there are presumably two underlying VPs with respect to (4):

(5) a. [vP [NP the man they were after] $\left[\mathrm{v}^{\prime}\right.$ believed [vp to be in hiding for a time]]]

b. [vP [NP the man they were after $]\left[\mathrm{v}^{\prime}\left[\mathrm{v}^{\prime}\right.\right.$ believed to be in hiding] for a time]]

When $\mathrm{V}^{\prime}$-reanalysis applies in (5a), the adverbial phrase, for a time, is included in the new complex $\mathrm{V}$ but it is not in (5b), because the reanalysis only incorporates material c-commanded by the verb. Hence when the new V is fronted, the NP is placed at the end in (5a), but it precedes the adverbial in (5b). This non-standard analysis of ECM can handle the adverbial argument under consideration, but it contradicts Larson's published claim that the ECM complement is IP.

\section{A-movement Analysis of HNPS}

Nishikawa (1990) claims that HNPS is the A-movement operation, which moves a heavy NP to the Spec of AgrP. He presents, as supporting evidence, examples in the Chichewa language, and argues that HNPS is the movement to the position that agrees with AgrO. Observe the following facts:

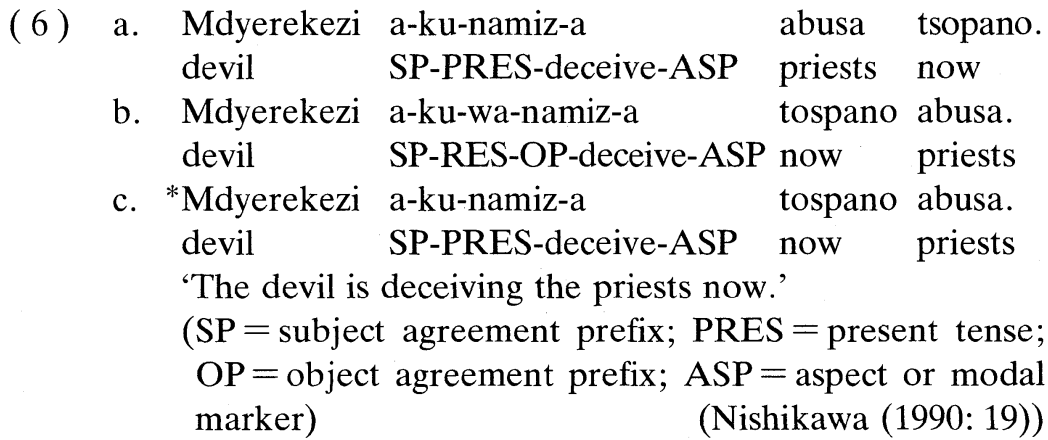
Chichewa has overt object agreement markers, and according to Baker (1988), when the object originates in the position which is adjacent to the verb, the object agreement does not occur. When the intervening

2 Note that Larson (1988a) claims that small clause constructions like I consider John foolish have an underlying VP in which the AP is sister to V. In this analysis the verb and the infinitive form a $V^{\prime}$ constituent that does not include the infinitive's subject. 
elements appear between the verb and its object as in (6b), the object agreement marker must appear on the verb. Nishikawa argues that if (6b) derives from the movement of NP, the moved NP is in the position which agrees with AgrO. Based on this, he claims that HNPS in English is also the movement to the Spec of $\mathrm{AgrP}$, as illustrated below:

( 7 )

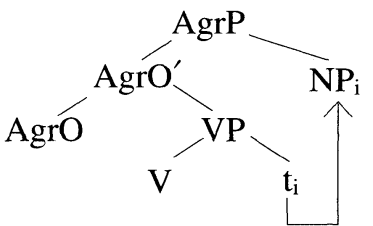

An immediate objection to the A-movement analysis presented by Nishikawa is raised by the licensing of parasitic gaps in English. It has been assumed in the literature that HNPS can license a parasitic gap, and the parasitic gap is licensed by $\mathrm{A}^{\prime}$-movement, not by A-movement. The following contrast confirms this claim.

(8) a. Which article did John file $t$ without reading $e$ ?

b. ${ }^{*}$ These articles were filed $t$ without my reading $e$.

c. I offended by not recognizing immediately my favorite uncle from Cleveland.

(Engdahl (1983: 12))

The A-movement analysis of HNPS predicts that (8c) is ungrammatical, on a par with the example in (8b). To solve this problem, Nishikawa argues that there is a process that creates a construction with two gaps, which does not depend on a syntactic movement for the second gap. Consider the following examples:

(9) a. I can't talk about these things to my father-in-law.

b. *I can't talk about $t$ to my father-in-law [the horrible dreams I've been having recently].

(Nishikawa (1990: 22))

c. John voted for $t$ although he disliked [the candidate who had been a butcher for many years].

(Nishikawa (1990: 22))

Nishikawa claims that the objects of prepositions may not undergo HNPS, as illustrated in (9b), whereas they may undergo Right Node Raising (hereafter RNR), following McCloskey's (1986) observation that a non-preposition-stranding language like Irish exceptionally allows preposition stranding by RNR. ${ }^{3}$ Then he concludes that $(9 \mathrm{c})$ is not

3 Williams (1986/1987) also argues that prepositions can be stranded by RNR. 
derived by the application of HNPS but by the application of RNR. By analogy Nishikawa claims that (8c) is also derived by the operation of RNR.

Closer inspection of the properties of HNPS, however, provides enough empirical evidence to argue that his analysis is not without its problems. $^{4}$ At this point describing the properties of HNPS is fruitful to the discussion. First, the dislocated NP shows Condition on Extraction Domain (CED) effects.

(10) a. John noticed a picture of his mother on the wall.

b. *Who did John notice on the wall a picture of?

(Rochemont (1992: 382))

(10) shows that the dislocated NP has the adjunct status. The Amovement analysis fails to account for the CED effects of HNPS.

Second, Larson (1988b) observes that HNPS in the double-object construction patterns with $\mathrm{A}^{\prime}$-movement with respect to the extraction from the direct and indirect objects. An indirect object NP may not undergo HNPS, nor may it undergo Wh-movement. ${ }^{5}$ Under the A-

4 The arguments against Nishikawa (1990) are also applicable to other Amovement analyses.

5 Some researchers argue that the claim that an indirect object may not undergo Wh-movement is questionable. Langendoen, Kalish-Landon and Dore (1976) collected data on English demonstrating that $22 \%$ of their subject population associated the extracted NP with the first possible gap site rather than the second in the sentences below.

(i) a. Who did you show the woman?

b. Who did you send the woman?

Beckman (1996) observes that speakers who accept the extraction of a Goal NP prefer to interpret the filler as the Goal NP especially when the postverbal NP is indefinite. Therefore they are skeptical of the claim that the extraction of the indirect object with Goal role is not possible. However, Hornstein and Weinberg (1981) point out that even those who accept (11c) find long extractions such as these in the following examples to be much worse:

(ii) *Who does John say Harry threw the ball?

(Hornstein and Weinberg (1981: 78)) Hornstein and Weinberg (1981) also cite more complex Wh-constructions, which are not acceptable.

(iii) a. *Harry, John threw the ball.

b. ${ }^{*}$ Harry is tough to throw the ball.

Stowell (1981) claims that (iv), which involves movement to an embedded COMP position, is as fully ungrammatical as other examples above.

(iv) *Wayne is the guy that Robert sent a telegram. 
movement analysis no explanation seems possible for this similarity between HNPS and $\mathrm{A}^{\prime}$-movement. We are thus left with an apparent symmetry between HNPS and $\mathrm{A}^{\prime}$-movement.

(11) a. What did you say you gave John?

b. ?Bill gave John yesterday the book that he was looking for.

c. *Who did you say you gave a book?

d. *Bill gave the book yesterday anyone who wanted it.

(Rochemont (1992: 383))

Third, as we have observed above, HNPS allows the construction which involves two gaps. Consider (8c), repeated here as (12):

(12) I offended by not recognizing immediately my favorite uncle from Cleveland.

A piece of counter-evidence, which has received little attention, against the RNR analysis of (12), is found in the sentences which produce island effects. If (12) is derived by the application of RNR, not HNPS, it will not observe so-called island effects. This is because only syntactic operations observe the island constraints. Wasow (personal communication), however, points out the following contrast. ${ }^{6}$

(13) a. *Pat asserted $t$ to someone who had denied PG [the claim we were discussing].

b. Pat asserted $t$ to someone who had denied it [the claim we were discussing].

According to Hudson (1992), whole extraction of the indirect object is not possible in British English.

(v) *Which authors did they give a prize?

(Hudson (1992: 258))

Note that partial extraction of the indirect object is possible in British English as in (vi).

(vi) Which book shall we give the author of a prize?

HNPS, on the other hand, is not applicable to the indirect object either in American English or in British English.

(vii) *Fred gave some flowers the girl he had met at the party the night before.

6 Postal (1994) presents the following example.

(British English) (Hudson (1992: 259))

(i ) Albert boasted at the office $t$ after firing the woman who had heard him boasting at home PG that his results were fantastic. (Postal (1994: 86)) The above example does not show the island effect. This is attributed to the fact that it does not involve the application of HNPS. Note that the dislocated element is not NP but CP. 
Notice that HNPS patterns with Wh-movement with regard to the island effects. Consider (14):

(14) a. *Pat asserted $t$ to someone who had denied PG the claim we were discussing.

b. *What did Pat assert $t$ to someone who had denied PG?

Compare in this connection the following examples. ${ }^{7}$

(15) a. ${ }^{*}$ Pat asserted $t$ to someone who had denied PG the claim we were discussing.

b. Mary knows a man who buys $e$, and Bill knows a man who sells $e$, picture of Fred.

(Erteschik-shir (1987: 107)) cited from Wexler and Culicover (1980)

(14) and (15) confirm that (12) is not derived by RNR, but $\mathrm{A}^{\prime}$ movement, since (14) and (15a) show the island effects.

Another piece of evidence further supports the claim that RNR does not apply to (12), but HNPS does. Consider the "Freezing" phenomenon, first observed by Wexler and Culicover (1980). While the phenomenon has received attention in the literature, the following difference in (16) has not been discussed. When NP appears in the sentence-final position after HNPS, the adjoined NP becomes frozen for extraction. RNR, on the other hand, does not show the Freezing phenomenon. (16) shows the difference in Freezing phenomenon between HNPS and RNR.

(16) a. ${ }^{*}$ Who did Pat sell, by not recognizing PG, pictures of $t$ ?

b. Who does Mary buy and Bill sell, pictures of $t$ ?

(Erteschik-shir (1987: 107)) cited from Wexler and Culicover (1980)

The fourth argument against the A-movement analysis concerns the interaction of HNPS with certain adverbs, which we have already

7 If there is an adverb between the PG and the postposed NP, the sentence sounds better.

(i) Pat asserted $t$ to someone who had denied PG all his life the claim we were discussing.

It is not clear to us why the sentence above is acceptable. We leave this as an unsolved problem. It is possible that the phenomenon seen here is related to the Adverb Effect, where it signals the parser that it is an environment in which the PG must be projected. As to the Adverb Effect, see Culicover (1993). 
presented. Under the A-movement analysis, the non-ambiguity of the adverbial phrases in (4b) is not accounted for. The heavy NP, which originates in the embedded subject position in the ECM construction, moves to the Spec of AgrP in the matrix clause under the A-movement analysis, while the adverbial remains in its original position. Then the A-movement analysis of HNPS offers no explanation for the nonambiguity of the adverbial phrase in (4b). An account of the nonambiguity of the adverbial phrase will be shown in Section 3 .

Fifth, the occurrence of the secondary predicate in the HNPS example questions the claim that HNPS is A-movement. Consider (17):

(17) I expect to be present sober the members of the group whom I respect very much.

According to Nakajima (1990), the secondary predicates are licensed if the modified NPs and the secondary predicates satisfy the mutual m-command requirement at S-structure. ${ }^{8}$ The moved NP and the secondary predicate in (17) fail to satisfy the mutual m-command requirement under the proposed A-movement analysis. Since the shifted NP occupies the Spec of AgrP in the matrix sentence, the secondary predicate in the embedded clause cannot $\mathrm{m}$-command the NP. This is inconsistent with the fact.

Finally, we want to argue that Nishikawa's observation on the parasitic gap, which is based on the difference in preposition stranding between HNPS and RNR, is falsified. Although Nishikawa argues that the objects of prepositions may not undergo HNPS, they actually do. Wasow (1995) argues that the objects of prepositions may undergo HNPS, pointing out the examples in (18).., 10

8 The mutual $\mathrm{m}$-command requirement does not apply at $\mathrm{D}$-structure, but at Sstructure. Otherwise the following contrast cannot be accounted for.

(i) a. John drank coffee hot.

b. ${ }^{*}$ Hot, John drank coffee.

9 Culicover (personal communication) argues that (18a) involves a parenthetical and may not be a case of HNPS. Many studies claim that the distribution of the parentheticals count as a test of constituency. The occurrence of the parenthetical in (18a) indicates that the dislocated NP is separated from the verb. Therefore we need to explain by what operation it is possible to separate the heavy NP and the verb.

10 Wasow (1995) takes these examples from corpora. 
(18) a. ... that would threaten a landowner's right to rely on, in good faith, a city's representation

b. I'll go over in my mind all the things I did wrong.

c. ... dinosaurs help children work through in makebelieve the issues they are grappling with daily

The V-P sequences in (18) are clearly not cases of verb-particle construction. ${ }^{11}$ We can test this by showing that the preposition cannot follow the object, and that the PPs in (18) can be coordinated with the PPs headed by other prepositions. Consider (19):

(19) a. ${ }^{*}$ I go it over in mind.

b. We go over our lines and through our dance steps.

c. I worked through my immediate problems and towards my long-term goals.

It is plausible to say that (18) and (19) indicate that the prediction that objects of prepositions cannot undergo HNPS, by any analysis, is actually an argument against the analysis.

\section{Rightward $\mathrm{A}^{\prime}$-Movement}

We have so far shown that Larson's analysis and Nishikawa's analysis are not as strong as previously thought. We have also argued that HNPS is $\mathrm{A}^{\prime}$-movement. We will argue here that under the rightward $\mathrm{A}^{\prime}$-movement the problems against the analyses discussed above will dissolve.

Under our view HNPS involves rightward movement and adjunction of NP to a maximal projection, and it observes the constraint proposed by Johnson (1985).

(20) Focus Movement Constraint (FMC)

Focus Movement adjoins a phrase $\mathrm{X}$ to the maximal projection immediately dominating $X$.

11 One might argue that (18) is derived by the restructuring of the $\mathrm{P}$ under $\mathrm{V}$, so that HNPS is not from a position within the PP. The restructuring analysis predicts that verbal forms, which permit pseudopassives, should allow HNPS of the same NP which can passivize. This analysis, however, faces a difficulty with the following examples.

(i) a. The apple pie was fought about by the children.

b. *The children fought about in a feverish way the delicious steaming apple pie baked by Uncle Frank.

(Postal (1986: 207)) 
(20) requires that the object of the verb, and the embedded subjects of ECM and small clause should be adjoined to the matrix VP and the embedded clause, respectively. ${ }^{12,13}$ (20) is well-motivated by (21)-(23).

12 The following example raises an apparent problem for our analysis.

(i) I'll consider $t$ to be fools in the weeks ahead all those who drop this course.

(Bresnan (1982: 423))

Bresnan (1982) claims that the adverbial PP, in the weeks ahead, modifies the matrix clause. The linear ordering of (i) indicates that the heavy NP is adjoined to the matrix clause, presumably to the matrix VP. If so, this is the violation of (20), which is inconsistent with the fact. Note that in the dialect that allows (i), (22b) and (23a) are also acceptable. We are left with the problem of explaining why they are acceptable in the dialect. I will not now explore, but only suggest one possible mechanism which salvages the derivation in the examples, while maintaining the condition (20). One such possibility is that some process may create a new position in VP, and the embedded subject moves to the position. Given this, movement from the newly created position to the matrix VP satisfies (20). Authier (1991) explores one such possibility. We will not pursue this matter further.

13 It is generally assumed that the Adjunction condition proposed by Chomsky (1986) excludes the adjunction of an element to an argument position, so Nakajima (1991) argues that the adjunction to the embedded small clauses, which consist of AgrP, is not possible. There are several objections possible to his analysis. Contrary to Nakajima's observation, there are several pieces of evidence which show that small clauses are not AgrP. The following diagnostic tests, which Nakajima employs, indicate that small clauses have IP property. Observe the parallelism between ECM and small clauses.

(i) a. ?I found people $t$ to be fascinating who had tons of money when I was still a child.

(Nakajima (1991: 40))

b. I consider anyone foolhardy who rides a motorcycle without a helmet.

c. He lets the cats out which were meowing.

d. I consider most people to be unattractive naked.

e. I consider most people unattractive naked.

Extraposition from subject has been assumed to attach extraposed elements to IP. (cf. Baltin (1978, 1981), Terazu (1979), Barss (1986), Nakajima (1989, 1991)). Given this assumption, the relative clause in the above example is attached to the embedded IP. Subject-oriented secondary predicates are supposed to be in IP. These facts indicate that small clauses are IP, and that the embedded IP is available as the adjunction site. Note that the following coordination fact also indicates that ECM and small clauses have the same categorical status.

(ii ) $\ldots$ he considers Mary homosexual and Jane to be nymphomaniac.

(Imai et al. (1989: 253))

The second objection to Nakajima's analysis is obtained from the following facts. (22a) and (23a) show that heavy NPs cannot adjoin to the matrix VP. Therefore the availability of (22c) and (23b) leads us to conclude that the embedded IPs are the available adjunction sites. If they consist of AgrPs, as Nakajima claims, we cannot account for (22c) and (23b). 
(21) a. It was believed by everyone that Mary bought for her mother an ornate Fourteenth Century gold ring.

b. ?It was believed that Mary bought for her mother an ornate Fourteenth Century gold ring by everyone.

c. *It was believed that Mary bought for her mother by everyone an ornate Fourteenth Century gold ring.

(Rochemont (1992: 386-387))

d. *Eleanor bought apparently brand new drapes for the whole house.

(Johnson (1985: 85))

(22) a. ${ }^{*}$ I believe $t$ to have quit without understanding it all the cheerful and friendly waitresses at Ken's Pub.

b. ${ }^{*}$ I considered $t$ to be faultless last night the paper on clitic climbing and metathesis. (Johnson (1985: 88))

c. ?I believe $t$ to have quit all the cheerful and friendly waitresses at Ken's Pub without understanding it.

(23) a. ?*John wants in New York on Monday every actor who has ever worked for him.

(Rochemont and Culicover (1990: 137))

b. ?John wants in New York every actor who has ever worked for him on Monday.

(20) is independently necessary to explain the strict locality of HNPS, which is not observable in the leftward movement. Unlike Whmovement, HNPS is phrase-bounded as shown above.

We are now ready to consider the properties shown in (10) and (12), which we have discussed in section 2 . On the assumption of (20) the heavy NP, which originates in the object position, is adjoined to the VP. This is confirmed by a syntactic test such as VP preposing.

(24) a. I said I would give to John everything that he demanded and give to John everything that he demanded I will.

b. *I said I would give to John everything that he demanded and give to John I will everything that he demanded.

The relevant structure of the HNPS example from the object position is roughly (25): 
(25)

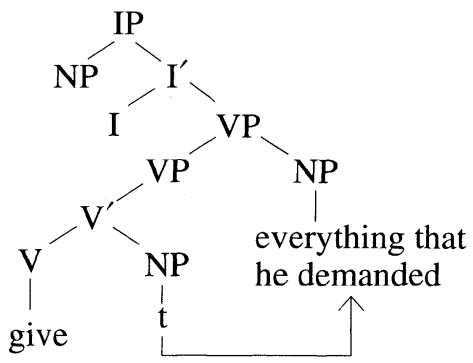

In the configuration of (25) the position to which the heavy NP is adjoined is $\mathrm{A}^{\prime}$-position, and it is an adjunct position. Therefore the property of (10) naturally follows. The property of (12) derives also from the configuration of (25). Since the adjoined VP is $\mathrm{A}^{\prime}$-position, the dislocated NP can license a parasitic gap.

Now consider the HNPS examples from the embedded ECM subjects, which are problematic for the previous analyses, repeated here as (26):

(26) a. The FBI believed to be in hiding for a time the man they were after.

b. I expect to be present sober the member of the group whom I respect very much.

FMC requires that the adjunction site of the embedded subject NP be the embedded IP. On the assumption that the adverbial phrase and the subject-oriented secondary predicates are sister-adjoined to IP, the relevant structures of $(26 a, b)$ are $(27 a, b)$, respectively:

(27) a.

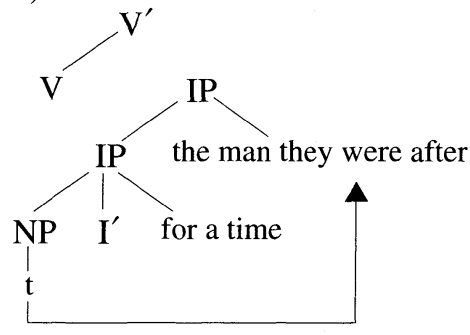

b.

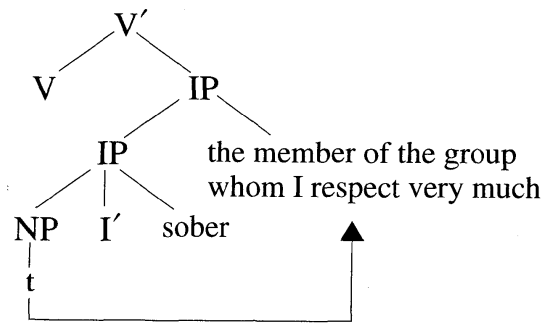

Given that adverbs modify their sisters (Pesetsky (1989) and Johnson (1991)), the adverbial phrase in (27a) correctly modifies the lower clause, which involves the shifted NP. The mutual m-command requirement on the subject and the secondary predicate holds in the structure of (27b). Thus (27b) is grammatical. 
FMC captures most of the properties of HNPS, but two problems still remain. ${ }^{14}$ One is the prohibition against the application of HNPS to the indirect objects in the double object construction. Another is the application of HNPS from a PP. Consider first the former case.

(28) a. ?Bill gave John yesterday the book that he was looking for.

b. *Bill gave the book yesterday anyone who wanted it.

Many attempts have been made by researchers to solve the puzzle in (28). Some argue that the puzzle in (28) can be captured by a syntactic constraint, while others argue that it can be by a thematic constraint. After pointing out the problems of the thematic solution to the puzzle, we propose a syntactic analysis, following Stowell (1981).

Fukuchi (1976) argues that the ungrammaticality of (28b) is due to the violation of the thematic constraint. Fukuchi argues that only a Theme NP can undergo HNPS, and that a Goal NP, which is placed before the PP with Theme role, resists HNPS. The examples below are, however, acceptable, according to my informants. The examples show that a Goal NP can undergo HNPS.

(29) a. The U.S government supplied with arms the government in Bosnia that is now fighting.

b. The man loaded with tons of hay the truck which he had rented from his friends.

The second objection to Fukuchi's analysis is that the thematic constraint can account for the impossibility of (28b), but not for that of (30). The thematic constraint provides no account of the similarity

14 The following examples raise an interesting apparent problem for our analysis.

(i) a. I have wanted [PRO to know $t]$ for many years exactly what happened to Rosa Luxemburg. (Postal (1974 in footnote 8: 92))

b. ${ }^{*}$ I have wanted [Bob to know $t$ ] for many years exactly what happened to Rosa Luxemburg.

(Nakajima (1984: 141))

The contrast shown above is not accounted for by FMC. However, given the process of restructuring, which is proposed by Rizzi (1982) and Nishikawa (1990), the above examples are not a potential problem for our analysis. Restructuring is an operation which turns a V-PRO-V sequence into a single verb in some situations. The configuration in which the embedded subject is a lexical NP resists restructuring, resulting in the ill-formedness of the second example. The first example, on the other hand, meets the context of restructuring. The well-formedness of the first example is attributed to the fact that it satisfies FMC because of restructuring. Note that some native speakers judge the starred example above as grammatically correct. The reason why this difference in judgement exists is not clear. We leave this for further contemplation. 
between HNPS and A'(leftward)-movement.

(30) *Who did you say you gave a book?

As is already observed, both Wh-movement and HNPS are A'movement. Therefore it is desirable that the ill-formedness of (28b) and (30) come from the violation of the same constraint.

The descriptive generalization that the indirect objects can undergo neither Wh-movement nor HNPS, as shown in (28) and (30), can be captured by an NP-Incorporation analysis (hereafter, NPIA) by Stowell (1981). Stowell (1981) assumes that a verb and its indirect object form a single complex verb by the application of the word-formation rule, that is, NP Incorporation. According to Baker (1988: 73) and Kayne (1991: 649), any element, which adjoins to an $X^{0}$, can no longer be separated from this $\mathrm{X}^{0}$. This requires that the syntactic movement be unable to analyze a subpart of a word. Therefore NPIA predicts that the movement of the indirect object to $\mathrm{A}^{\prime}$-position is not possible. This is consistent with the facts. ${ }^{15}$ NPIA also correctly predicts that (29) is possible. Since the NP, which is next to the verb, is the true syntactic object of the verb, NPIA does not apply to (29).

NPIA may be extended to another range of data pointed out by Larson (1991). He points out the similarities between the verb with double objects and the verb, promise. Given NPIA, we can correctly exclude the ungrammatical cases in (31).

(31) a. John promised Mary a sports car.

b. ${ }^{*}$ John promised a sports car the man whom he liked very much.

c. John promised many villagers who were kind to him to come back.

d. ${ }^{*}$ John promised to come back many villagers who were kind to him.

Now return to the extraction from PP. In section 2 we have shown that the objects of prepositions may undergo HNPS. An unsettled problem is the contrast between the examples below. In some cases HNPS strongly resists preposition stranding and demands pied-piping of the PP.

15 We have seen in footnote 5 that partial extraction of the indirect NP is possible in British English. At this time we have no account of this fact. We leave this matter open. 
(32) a. ... that would threaten a landowner's right to rely on, in good faith, a city's representation

b. I'll go over in my mind all the things I did wrong.

a. *I talked to yesterday all of the teachers.

b. I talked yesterday to all of the teachers.

The above difference may be attributed to how strongly the verb and the PP are connected. (34) suggests this possibility. ${ }^{16}$

(34) a. ${ }^{*}$ I talked to all of the teachers, but Mary did an English teacher.

b. I talked to all of the teachers, but Mary did to an English teacher.

c. They went over their lines, and we will(,) our dance steps.

d. They worked through all of the problems they had, and we will(,) our immediate problems.

As the contrast between (34a) and (34b) shows, pseudogapping cannot delete the preposition in the talk-to type. The facts concerning pseudogapping indicate that there is a difference in the connection of a verb with a PP.

\section{Concluding Remarks}

After discussing the previous studies on HNPS, we have clarified the problems of those analyses, and we have seen, through the discussions, that rightward $\mathrm{A}^{\prime}$-movement provides a more consistent treatment of HNPS examples. Given the rightward $\mathrm{A}^{\prime}$-movement analysis, the properties of HNPS can be accounted for. FMC has provided an account of the upwardness of HNPS, the distribution of the adverbial phrase of HNPS examples in the ECM construction, and the licensing of the secondary predicates in HNPS examples. The adjunct status of the dislocated NP and the similarities in licensing the parasitic gap between HNPS and $\mathrm{A}^{\prime}$-movement have provided additional support for $\mathrm{A}^{\prime}$-movement analysis of HNPS. We have also discussed some other

16 Both types in (34) may undergo pseudopassive.

(i) a. All of the teachers were talked to.

b. Everything you need for this task has been gone over in class.

c. All of our difficulties have now been worked through. 
characteristics of HNPS examples. We have shown that NPIA captures the impossibility of HNPS of the first object in the double object construction, and we have suggested that HNPS from a PP is closely related to how strongly a verb and a PP are connected.

\section{REFERENCES}

Authier, J.-Marc (1991) "V-Governed Expletives, Case Theory, and the Projection Principle," Linguistic Inquiry 22, 721-740.

Baker, Mark (1988) Incorporation: A Theory of Grammatical Function Changing, University of Chicago Press, Chicago.

Baltin, Mark (1978) Toward a Theory of Movement Rules, Doctoral dissertation, MIT.

Baltin, Mark (1981) "Strict Bounding," The Logical Problem of Language Acquisition, ed. by Mark Baker, Carl Lee and John McCathy, 275-295, MIT Press, Cambridge, MA.

Barss, Andrew (1986) Chain and Anaphoric Dependence, Doctoral dissertation, MIT.

Beckman, Jill (1996) "Double Objects, Definiteness, and Extraction: A Processing Perspective," University of Massachusetts Occasional Papers 19, 27-69.

Bresnan, Joan (1982) "Control and Complementation," Linguistic Inquiry 13, 343-434.

Chomsky, Noam (1986) Barriers, MIT Press, Cambridge, MA.

Culicover, Peter W. (1993) "Evidence against ECP Accounts of the That-T Effect," Linguistic Inquiry 24, 557-561.

Culicover, Peter W. and Michael Rochemont (1990) "Extraposition and the Complement Principle," Linguistic Inquiry 21, 23-47.

Engdahl, Elisabet (1983) "Parasitic Gaps," Linguistics and Philosophy 6, 5-34.

Erteschik-shir, Nomi (1987) "Right Node Raising," MIT Working Papers in Linguistics 10, 105-117.

Fukuchi, Hajime (1976) "Complex NP Shift and Trace Theory," Eibungaku Kenkyuu (Studies in English Literature), 52, 95-118.

Hornstein, Norbert and Amy Weinberg (1981) "Case Theory and Preposition Stranding," Linguistic Inquiry 12, 55-91.

Hudson, Richard (1992) "So-called 'Double Objects' and Grammatical Relations," Language 68, 251-276.

Imai Kunihiko, Heizo Nakajima, Shigeo Tonoike, Kimiya Adachi, and Hajime Fukuchi (1989) Ippo Susunda Eibunpo (Who's Afraid of Bars and Barriers), Taishukan, Tokyo.

Johnson, Kyle (1985) A Case for Movement, Doctoral dissertation, MIT.

Johnson, Kyle (1988) "Clausal Gerunds, the ECP, and Government," Lin- 
guistic Inquiry 19, 583-609.

Johnson, Kyle (1991) "Object Positions," Natural Language and Linguistic Theory 9, 577-636.

Kayne, Richard (1991) "Romance Clitic, Verb movement, and PRO," Linguistic Inquiry 22, 647-689.

Langendoen, D. Terence, Nancy Kalish-Landon, and John Dore (1976) "Dative Questions: A Study in the Relation of Acceptability of an English Sentence Type," An Integrated Theory of Linguistic Ability, ed. by G. Thomas Bever, Jerrold J. Kats, and D. Terence Langendoen, 195-223, Thomas Y. Crowell Company, New York.

Larson, Richard (1988a) "On the Double Object Construction," Linguistic Inquiry 19, 335-391.

Larson, Richard (1988b) "Light Predicate Raising," ms., MIT.

Larson, Richard (1991) "Promise and the Theory of Control," Linguistic Inquiry 22, 103-139.

McCloskey, James (1986) "Right Node Raising and Preposition Stranding," Linguistic Inquiry 17, 183-186.

Nakajima, Heizo (1984) "Comp as a SUBJECT," The Linguistic Review 4, 121-152.

Nakajima, Heizo (1989) "Bounding of Rightward Movements," Linguistic Inquiry 20, 328-334.

Nakajima, Heizo (1990) "Secondary Predication," The Linguistic Review 7, 275-309.

Nakajima, Heizo (1991) "Reduced Clauses and Argumenthood of AgrP," Topics in Small Clauses, ed. by Heizo Nakajima and Shigeo Tonoike, 39-57, Kurosio, Tokyo.

Nakamura, Yoshio (1991) "A Movement Analysis of Heavy NP Shift," Explorations in English Linguistics 7, 55-68.

Nishikawa, Yoshitaka (1990) "Evidence for the Existence of AgrP: Heavy NP Shift," English Linguistics 7, 14-31.

Pesetsky, David (1989) "Language-Particular Processes and the Earlier Principle," ms., MIT.

Postal, Paul (1974) On Raising, MIT Press, Cambridge, MA.

Postal, Paul (1986) Studies of Passive Clauses, State University of New York Press, Albany.

Postal, Paul (1994) "Parasitic and Pseudoparasitic Gaps," Linguistic Inquiry 25, 63-117.

Rizzi, Luigi (1982) Issues in Italian syntax, Foris, Dordrecht.

Rochemont, Michael (1992) "Bounding Rightward A'-dependencies," Island Constraints: Theory, Acquisition and Processing, ed. by Helen Goodluck and Michael Rochemont, 373-395, Kluwer Academic Publishers, Dordrecht.

Rochemont, Michael and Peter W. Culicover (1990) English Focus Constructions and The Theory of Grammar, Cambridge University Press, Cam- 
bridge.

Stowell, Timothy (1981) Origins of Phrase Structure, Doctoral dissertation, MIT.

Terazu, Noriko (1979) "A Note on the Derived Structure of Extraposition Rules," Studies in English Linguistics 7, 85-98.

Wasow, Thomas (1995) "Heavy NP Shift: Some Observations and Problems," ms., Stanford University, California.

Wexler, Kenneth and Peter W. Culicover (1980) Formal Principles of Language Acquisition, MIT Press, Cambridge, MA.

Williams, Edwin (1986/1987) "The ATB Theory of Parasitic Gaps," The Linguistic Review 6, 265-279.

Department of English

Nagasaki University

1-14 Bunkyo-machi, Nagasaki, 852

e-mail: t-nishi@net.nagasaki-u.ac.jp 